\title{
Association of Secondary Hyperparathyroidism with CKD Progression, Health Care Costs and Survival in Diabetic Predialysis CKD Patients
}

\author{
Glen T. Schumock ${ }^{\mathrm{a}}$ Dennis L. Andress ${ }^{\mathrm{b}}$ Steven E. Marx ${ }^{\mathrm{b}}$ Raimund Sterz ${ }^{\mathrm{b}}$ \\ Amie T. Joyce ${ }^{c}$ Kamyar Kalantar-Zadeh ${ }^{d}$ \\ ${ }^{a}$ Center for Pharmacoeconomic Research, University of Illinois at Chicago, Chicago, Ill., b Abbott, Abbott Park, III., \\ 'PharMetrics Inc., Watertown, Mass., and d Harold Simmons Center for Kidney Disease Research and Epidemiology, \\ Los Angeles Biomedical Research Institute at Harbor-UCLA Medical Center, Torrance, Calif., USA
}

\section{Key Words}

Chronic kidney disease $\cdot$ Diabetes $\cdot$ Hyperparathyroidism $\cdot$ Costs

\begin{abstract}
Background/Aims: The objective of this study was to examine health care costs and utilization and the risks of dialysis or mortality among diabetic predialysis chronic kidney disease (CKD) patients with and without secondary hyperparathyroidism (SHPT). Methods: This retrospective, matched cohort study examined insurance claims from 703 adult diabetic predialysis CKD patients with and without SHPT during a 72-month follow-up period. Annualized estimates of health care service utilization, costs and disease progression to dialysis or death following index CKD diagnosis were compared. Results: Preindex (baseline) characteristics were similar between the cohorts. Postindex numbers of prescription utilization, outpatient service utilization and hospitalizations were all higher $(p<0.0001)$ in diabetic CKD patients with SHPT compared to those without SPHT in both unadjusted and adjusted analyses even after multivariate adjustment for known confounders. The rate of progression to dialysis or death was higher for diabetic CKD patients with SHPT compared to those without SPHT. Those with SHPT were at higher risk of requiring dialysis treatment [hazard ratio $(\mathrm{HR})=6.7 ; 95 \%$ confidence interval $(\mathrm{Cl})=4.3-10.6]$ and
\end{abstract}

death ( $\mathrm{HR}=2.3 ; 95 \% \mathrm{Cl}=1.1-4.9)$ compared to those without SHPT. Conclusion: In diabetic predialysis CKD patients, the presence of SHPT is associated with significantly greater health care resource utilization and costs, and a faster rate of disease progression.

Copyright $\odot 2009$ S. Karger AG, Basel

\section{Introduction}

Diabetes mellitus (DM) has recently been referred to as an epidemic in the USA because of its rapidly increasing prevalence and because of the staggering morbidity and mortality toll that it imparts [1]. In 2005, 20.8 million Americans (7.0\% of the population) had diabetes; the number of new DM cases per annum increased by nearly $300 \%$, from just under a half million in 1980 to 1.4 million in 2005 [2, 3]. It is known to be associated with numerous complications including heart disease, stroke, hypertension, nervous system disease and chronic kidney disease (CKD), also known as diabetic nephropathy

Portions of this study have been presented in abstract form at the Endocrine Society Meeting, Toronto, Ont., Canada, June 5, 2007, and the American Society of Health System Pharmacists' Annual Meeting, San Francisco, Calif., USA, June 26, 2007.

\section{KARGER}

Fax +41613061234 E-Mail karger@karger.ch www.karger.com
Glen Schumock

Center for Pharmacoeconomic Research

833 S. Wood St. (M/C 886)

Chicago, IL 60612 (USA)

Tel. +1 312996 7961, Fax +1 312996 0379, E-Mail schumock@uic.edu 
$[2,4]$. In 2004, DM was the sixth leading cause of death in the USA [4].

About one third of people with DM will eventually develop CKD [5]. The CKD risk is even greater in African Americans, Asians, Hispanics and Native Americans [5]. The risk of developing CKD also increases with the length of time a person has had DM. Indeed DM is the single leading cause of end-stage kidney failure, i.e. CKD stage 5 , in the USA, accounting for about $44 \%$ of people who start maintenance dialysis treatment each year [2]. The prevalence of stage 3-5 CKD has been reported to be $15 \%$ in individuals with $\mathrm{DM}$, which is significantly higher than those without DM (4\%) [6]. Furthermore, it is likely that CKD is underreported in those with DM because current screening strategies based on creatinine or albuminuria likely fail to identify a considerable number of subjects with early CKD stages [7].

Individuals with concomitant $\mathrm{DM}$ and $\mathrm{CKD}$ are at greater risk for cardiovascular disease $(\mathrm{CV})$ and premature mortality compared to those with either disease alone [1]. Furthermore, secondary hyperparathyroidism (SHPT) often develops in patients with CKD and may lead to greater morbidity and higher health care costs in these individuals [8]. However, the additional burden caused by SHPT in those with both DM and CKD not yet requiring dialysis treatment has not been described in the literature.

The purpose of this study was to describe the cost, health care resource utilization and disease progression of diabetic CKD patients with SHPT, who did not receive vitamin $\mathrm{D}$ receptor activation (VDRA) therapy. The specific objectives were: (1) to compare baseline (pre-CKD) characteristics in diabetic CKD patients with and without SHPT; (2) to estimate and compare resource utilization and health care costs among these individuals, including CKD-related and CV-related utilization and costs, and (3) to determine the additional risk of CKD progression to dialysis stage or to all-cause mortality associated with SHPT.

\section{Methods}

\section{Data Sources}

We conducted a retrospective matched cohort study using an administrative claims database. The data were obtained from the PharMetrics ${ }^{\mathrm{TM}}$ Patient-Centric Database, which included claims for patients from over 90 health plans across the USA (PharMetrics Inc., a unit of IMS, Watertown, Mass., USA). The database included inpatient and outpatient diagnoses according to the International Classification of Diseases, 9th Revision (ICD-9), Clinical Modification format, and the procedures according to the
Current Procedural Terminology, 4th edition, and Healthcare Common Procedural Coding System formats, as well as prescription records, including retail and mail order. Additional data elements were: demographic variables including age, gender and geographic region; insurance type, e.g. health maintenance organizations, preferred provider organizations; payer type, e.g. commercial versus self-pay; provider specialty, and patient start and stop dates for plan enrollment.

\section{Selection of the Study Population}

We chose to examine claims from a 72-month period (from January 1, 1999, to December 31, 2004) in order to identify adult diabetic predialysis CKD patients with $(n=264)$ or without $(n=$ 16,211) SHPT. From these patients identified, diabetic CKD patients with no evidence of SHPT were then matched, based on age (5-year intervals), gender, duration of follow-up (30-day intervals) and Charlson comorbidity index, to diabetic CKD patients with SHPT. After matching there were 517 adult diabetic predialysis CKD patients without SHPT (cohort 1) and 186 adult diabetic predialysis CKD patients with SHPT (cohort 2). DM was assumed when a patient had 2 or more diagnoses for DM (250.XX) 30 days or more apart or at least 1 claim for an oral antidiabetic or insulin prescription during the preindex period. CKD was defined based on the ICD-9 codes $(585,586,587.403 . X X, 404 . X X .250 .4 X, 582 . X$, 583.XX, 588.XX, 593.9, 580.XX, 581.XX, 582.XX, 589.XX, 593.7, 753.1X, 753.0 and 753.3) [9].

To be included in the analyses, we stipulated that patients needed to be continuously enrolled in a health plan for at least 12 months prior and at least 6 months after the first CKD medical or facility claim. An 'index date', defined as the date associated with the initial medical or facility claim meeting the above-mentioned ascertainment criteria, was assigned to each individual patient. The follow-up period, at least 6 months after the index date, was censored as of the date of health plan disenrollment, the end of available data, initiation of dialysis or the end of the study period. The preindex period was defined as the time prior to this first medical or facility claim for CKD, and the postindex one was defined as the time thereafter.

Patients were excluded if: (a) they were less than 18 years of age at the index date, (b) their health plan did not provide data for pharmacy days supply, (c) they were enrolled less than 12 months prior to the index date, (d) they were enrolled less than 6 months after the index date, (e) they were diagnosed as having SHPT during the preindex period, (f) they were 65 years or older and not enrolled in a 'Medicare risk' plan (because complete claims histories during intervals of continuous enrollment may not be available for individuals aged 65 years or older whose insurance coverage is not Medicare 'risk' due to issues of coordination of benefits with traditional Medicare or another payer), (g) key variables were missing in their patient record, e.g. missing or invalid values in gender, birth year or enrollment date variables, or $(h)$ received a prescription for active or activated VDRA therapy. Patients who were treated with VDRA therapy before or after the index date were excluded.

\section{SHPT Ascertainment}

Predialysis diabetic CKD patients were considered to have a diagnosis of SHPT if they had: (a) a diagnosis of SHPT (26\%; based on at least one medical or facility claim indicative of the diagnosis, ICD-9 code $588.8 \mathrm{x})$, (b) a diagnosis of hyperphosphatemia (16\%; 
based on at least one medical or facility claim indicative of the diagnosis, ICD-9 code 275.3) or (c) evidence of treatment with a phosphate binder (62\%; based on at least one pharmacy claim).

\section{Dialysis Outcome Ascertainment}

Because we sought to examine exclusively predialysis diabetic CKD patients, any patient undergoing maintenance dialysis treatment during the follow-up period was censored on the day prior to the first chronic dialysis treatment. For these patients, their cohort assignment was based on claims presented prior to the censoring event, and their follow-up period for evaluating resource utilization, costs and outcome measures ended on the same day.

\section{Death Ascertainment}

Since the database did not provide an indicator of death, a previously published proxy procedure was used [10]. This procedure includes the examination of all postindex utilizations on a monthto-month basis for each patient. Patients with less than 12 months of claims activity and an event likely to have been fatal (e.g. cardiac arrest, resuscitation or hospitalization) during the last month in which medical and pharmacy claims were available were assumed to have died. This method has been validated and used elsewhere $[11,12]$.

\section{Creation of Cohorts}

Patients who met the clinical and enrollment criteria noted above were assigned to one of the two mutually exclusive cohorts. Cohort assignment was based on the diagnosis of SHPT and treatment with VDRA as follows: cohort 1 included patients with no evidence of SHPT or VDRA therapy, and cohort 2 encompassed patients with evidence of SHPT and no VDRA therapy.

\section{Statistical Analyses and Measures}

Preindex (baseline) demographic and clinical characteristics were evaluated for the two patient cohorts. The following characteristics were evaluated based on data obtained on the index date or during the preindex period: index age, gender, insurance type, geographic region, preindex comorbidities, Charlson comorbidity index and total preindex health care costs.

Annualized per patient resource utilization and direct health care costs were reported for each of the cohorts during the followup period up to the time of dialysis censoring. The number of prescriptions, outpatient services, and hospitalizations were reported for each cohort. Utilization was divided into CV-related or non-CV-related subcategories. CV-related care was further categorized based on the clinical codes on the claims of interest. All other utilization and costs were categorized as non-CV-related health care. Because the follow-up time was varied, all total and $\mathrm{CV}$-related utilization measures and costs were annualized. The total costs, i.e. plan payments for services rendered, were expressed in 2004 US dollars as the amount paid by the health plan, and were adjusted as necessary using the medical care component of the US Consumer Price Index.

We used negative binomial distribution for utilization and a gamma distribution for cost. A log link function was used to adjust the descriptive analyses for potential confounders including gender, age, plan type, payer type, geographic region, physician specialty, preindex comorbidities and preindex total health care costs.
Time to dialysis and time to death were compared between the two cohorts using Wilcoxon rank-sum tests for continuous variables. Kaplan-Meier survival analyses comparing time to dialysis and death among the cohorts were also conducted, as were Cox proportional hazard survival regression analyses. Cox proportional hazard models were adjusted for age, gender, geographic region, plan type, payer type, physician specialty, preindex comorbidities and preindex costs. For all analyses, the diabetes plus CKD without SHPT group was used as the reference cohort.

\section{Results}

\section{Baseline (Preindex) Comparisons}

Table 1 provides preindex characteristics of the two cohorts compared in this analysis. A total of 703 diabetic CKD patients were included, among whom 186 bore the concomitant diagnosis of SHPT and 517 did not. The cohorts did not differ with respect to age, gender, type of insurance or geographic region (type of insurance and geographic region not shown in the table).

Preindex comorbidities were also similar, with the exception of circulatory system disorders (79 vs. $87 \%$ in those without SHPT and those with SHPT, respectively; $\mathrm{p}=0.023)$ and pregnancy/childbirth/puerperium disorders ( 0.2 vs. $1.6 \%$ in those without SHPT and those with SHPT; $\mathrm{p}=0.027$ ) being different. The total number of comorbidities per patient was the same (5.12 vs. 5.13 in those without SHPT and those with SHPT; $\mathrm{p}=0.81$ ). However, the preindex Charlson comorbidity index was higher in the group with SHPT (1.98 vs. 2.26 in those without SHPT and those with SHPT; $p=0.039)$. Preindex total health care costs, i.e. prescriptions, outpatient and inpatient services, were also slightly higher in the group with SHPT, but this was not statistically significant, i.e. USD 16,604 versus USD 19,070 in those without SHPT and those with SHPT, respectively $(\mathrm{p}=0.3)$.

\section{Descriptive Comparison of Postindex Utilization and Costs}

As shown in table 2, the two cohorts differed significantly across nearly all measures of health care utilization. Diabetic CKD patients with SHPT filled more total prescriptions compared to those without SHPT (75.6 vs. $54.6, \mathrm{p}<0.0001)$, and a greater proportion of those prescriptions were for CV-related medications (34.5 vs. 30.6\%). Diabetic CKD patients with SHPT also received a greater number of outpatient services (121.4 vs. 76.4, $\mathrm{p}<0.0001$ ), and again a greater proportion of these services was for CV-related care (47.6 vs. $36.8 \%$ ) compared to diabetic CKD patients without SHPT. CV-related in- 
Table 1. Comparison of preindex clinical characteristics across the two cohorts of diabetic individuals with CKD

\begin{tabular}{lccc}
\hline Baseline characteristics & Cohort 1: SHPT absent & Cohort 2: SHPT present & p value $^{\mathrm{a}}$ \\
\hline Total patients & $517(74)$ & $186(26)$ & 0.45 \\
Mean age, years & $54.9 \pm 8.8$ & $54.5 \pm 10.4$ & 0.52 \\
Female gender & $225(44)$ & $86(46)$ & 0.58 \\
\hline Preindex comorbidities & & & 0.10 \\
Infectious and parasitic diseases & $104(20)$ & $41(22)$ & 0.28 \\
Neoplasms & $84(16)$ & $21(11)$ & 0.08 \\
Endocrine/metabolic/immune disorders & $515(99)$ & $184(99)$ & 0.18 \\
Blood and blood-forming organ disorders & $87(17)$ & $42(23)$ & 0.35 \\
Mental disorders & $110(21)$ & $31(17)$ & 0.02 \\
Nervous system and sense organ disorders & $274(53)$ & $106(57)$ & 0.52 \\
Circulatory system disorders & $408(79)$ & $161(87)$ & 0.22 \\
Respiratory system disorders & $236(46)$ & $90(48)$ & 0.42 \\
Digestive system disorders & $170(33)$ & $52(28)$ & 0.03 \\
Genitourinary system disorders & $215(42)$ & $71(38)$ & 0.85 \\
Pregnancy/childbirth/puerperium disorders & $1(0.2)$ & $3(1.6)$ & 0.47 \\
Skin/subcutaneous tissue disorders & $165(32)$ & $58(31)$ & $95(51)$ \\
Musculoskeletal system disorders & $280(54)$ & & 0.81 \\
\hline Number of comorbidities per patient & & $5.13 \pm 1.97$ & 0.04 \\
Mean \pm SD & $5.12 \pm 2.16$ & $2.26 \pm 1.40$ & 0.3 \\
Charlson comorbidities index & $1.98 \pm 1.08$ & $19,070 \pm 40,964$ & \\
Preindex total health care costs ${ }^{\mathrm{b}}$, USD & $16,604 \pm 33,519$ & &
\end{tabular}

Figures in parentheses are percentages.

${ }^{a}$ Differences between cohorts were analyzed using the $\chi^{2}$ for categorical variables and Wilcoxon rank-sum tests for continuous variables.

${ }^{\mathrm{b}}$ For 12-month preindex period.

patient care was also higher in the cohort with SHPT. CV-related days in hospital were much higher (20.8 vs. $6.2, \mathrm{p}<0.0001)$ as were hospitalizations $(2.5$ vs. $0.8, \mathrm{p}<$ 0.0001) for those with SHPT compared to those without SHPT.

Table 2 compares postindex costs between the two cohorts. Diabetic CKD patients with SHPT had significantly greater medication costs, outpatient service costs and hospital-related costs. Total medication costs were USD 5,492 versus USD 3,589 ( $\mathrm{p}<0.0001$ ), total outpatient costs were USD 10,921 versus USD 7,191 ( $\mathrm{p}<0.0001)$, and total inpatient costs were USD 74,951 versus USD 19,618 $(\mathrm{p}<0.0001)$, in those with SHPT compared to those without SHPT. Again, CV-related total costs were greater (USD 80,383 vs. USD 22,586, $\mathrm{p}<0.0001$ ) for diabetic CKD patients with SHPT compared to those without SHPT.

\section{Adjusted Comparison of Postindex Utilization and Costs}

To account for differences in the baseline (preindex) characteristics of patients in the two cohorts, we conducted an adjusted comparison of postindex utilization and costs by controlling for selected covariates, including gender, age, plan type, payer type, geographic region, physician specialty, preindex comorbidities and preindex total health care costs. Health care utilization and costs were higher in the cohort with SHPT compared to that without SHPT. Total prescription utilization, total outpatient services and hospitalizations were 135\% ( $\mathrm{p}<0.0001), 164 \%(\mathrm{p}<0.0001)$ and 354\% ( $<<$ $0.0001)$ higher, respectively, in diabetic CKD patients with SHPT compared to those without SHPT. The percentage differences for CV-related prescriptions, outpatient and hospitalizations were $139 \%(\mathrm{p}=0.0002), 203 \%$ $(\mathrm{p}=0.0002)$ and $343 \%(\mathrm{p}<0.0001)$ higher in diabetic patients with SHPT than diabetic CKD patients without 
Table 2. Descriptive comparison of annual costs and services of prescriptions, and outpatient and inpatient care (means \pm SD)

\begin{tabular}{|c|c|c|c|c|c|c|}
\hline \multirow{2}{*}{$\begin{array}{l}\text { Prescription or medical } \\
\text { costs and services }\end{array}$} & \multicolumn{3}{|l|}{ Services } & \multicolumn{3}{|l|}{ Costs $^{2}$} \\
\hline & $\begin{array}{l}\text { cohort 1: diabe- } \\
\text { tes plus CKD } \\
\text { without SHPT }\end{array}$ & $\begin{array}{l}\text { cohort 2: diabe- } \\
\text { tes plus CKD } \\
\text { with SHPT }\end{array}$ & $\begin{array}{l}\mathrm{p} \\
\text { value }^{1}\end{array}$ & $\begin{array}{l}\text { cohort 1: diabetes } \\
\text { plus CKD without } \\
\text { SHPT }\end{array}$ & $\begin{array}{l}\text { cohort 2: diabetes } \\
\text { plus CKD with } \\
\text { SHPT }\end{array}$ & $\begin{array}{l}\mathrm{p} \\
\text { value }^{1}\end{array}$ \\
\hline \multicolumn{7}{|l|}{ Medication $^{3}$} \\
\hline CV-related medications & $16.7 \pm 14.6$ & $26.1 \pm 21.7$ & $<0.0001$ & $751 \pm 4,525$ & $1,096 \pm 1,174$ & 0.0001 \\
\hline Hypertension medications & $12.7 \pm 11.8$ & $22.2 \pm 18.8$ & $<0.0001$ & $400 \pm 504$ & $742 \pm 846$ & $<0.0001$ \\
\hline Hyperlipidemia medications & $3.9 \pm 5.1$ & $3.8 \pm 5.5$ & 0.24 & $351 \pm 454$ & $354 \pm 537$ & 0.28 \\
\hline Non-CV-related medications & $37.9 \pm 31.1$ & $49.5 \pm 35.9$ & $<0.0001$ & $2,838 \pm 4,370$ & $4,396 \pm 7,949$ & 0.0004 \\
\hline Total medications & $54.6 \pm 40.1$ & $75.6 \pm 47.7$ & $<0.0001$ & $3,589 \pm 4,525$ & $5,492 \pm 8,171$ & $<0.0001$ \\
\hline \multicolumn{7}{|l|}{ Outpatient services ${ }^{4}$} \\
\hline CV-related outpatient & $28.1 \pm 39.0$ & $57.8 \pm 63.9$ & $<0.0001$ & $2,374 \pm 4,943$ & $4,876 \pm 10,138$ & $<0.0001$ \\
\hline CV-related emergency room & $0.2 \pm 0.8$ & $0.8 \pm 2.9$ & $<0.0001$ & $172 \pm 602$ & $336 \pm 1,005$ & 0.0004 \\
\hline CV-related physician office visits & $5.6 \pm 9.8$ & $12.4 \pm 22.7$ & $<0.0001$ & $439 \pm 928$ & $1,177 \pm 2,731$ & $<0.0001$ \\
\hline CV-related laboratory/radiology & $14.3 \pm 18.4$ & $29.8 \pm 32.2$ & $<0.0001$ & $515 \pm 1,122$ & $736 \pm 811$ & $<0.0001$ \\
\hline Other CV-related outpatient & $7.9 \pm 18.1$ & $14.9 \pm 20.9$ & $<0.0001$ & $1,248 \pm 3,911$ & $2,628 \pm 9,007$ & $<0.0001$ \\
\hline Non-CV-related outpatient & $48.2 \pm 60.5$ & $63.5 \pm 57.4$ & $<0.0001$ & $4,817 \pm 8,870$ & $6,044 \pm 9,133$ & 0.0006 \\
\hline Non-CV-related emergency room & $0.4 \pm 0.9$ & $0.6 \pm 1.3$ & 0.013 & $220 \pm 680$ & $369 \pm 1,033$ & 0.03 \\
\hline Non-CV-related physician office visits & $13.5 \pm 20.8$ & $19.0 \pm 26.7$ & 0.0004 & $852 \pm 1,438$ & $1,097 \pm 1,474$ & 0.0003 \\
\hline Non-CV-related laboratory/radiology & $17.8 \pm 33.4$ & $23.3 \pm 21.4$ & $<0.0001$ & $980 \pm 2,577$ & $966 \pm 1,652$ & 0.01 \\
\hline Other non-CV-related outpatient & $16.5 \pm 23.5$ & $20.6 \pm 26.4$ & 0.0304 & $2,765 \pm 6,893$ & $3,612 \pm 8,224$ & 0.02 \\
\hline Total outpatient services & $76.4 \pm 83.3$ & $121.4 \pm 100.1$ & $<0.0001$ & $7,191 \pm 10,952$ & $10,921 \pm 15,741$ & $<0.0001$ \\
\hline \multicolumn{7}{|l|}{ Inpatient services ${ }^{4}$} \\
\hline CV-related inpatient & $6.2 \pm 33.6$ & $20.8 \pm 52.3$ & $<0.0001$ & $19,461 \pm 146,685$ & $74,411 \pm 287,613$ & $<0.0001$ \\
\hline Non-CV-related inpatient & $0.8 \pm 4.2$ & $2.5 \pm 5.5$ & $<0.0001$ & $157 \pm 1,127$ & $542 \pm 3,078$ & 0.11 \\
\hline Total inpatient services & $0.8 \pm 4.2$ & $2.6 \pm 5.6$ & $<0.0001$ & $19,618 \pm 146,737$ & $74,953 \pm 287,593$ & $<0.0001$ \\
\hline Total CV-related & - & - & - & $22,586 \pm 146,964$ & $80,383 \pm 288,819$ & $<0.0001$ \\
\hline Total non-CV-related & - & - & - & $7,812 \pm 11,578$ & $10,982 \pm 14,811$ & $<0.0001$ \\
\hline Grand total & - & - & - & $30,398 \pm 146,736$ & $91,365 \pm 290,243$ & $<0.0001$ \\
\hline \multicolumn{7}{|c|}{$\begin{array}{l}{ }^{1} \text { Differences between cohorts were analyzed using Wilcoxon rank-sum tests for continuous variables. } \\
{ }^{2} \text { Values are USD expressed in } 2004 . \\
{ }^{3} \text { Values shown in annual number of prescription claims. } \\
{ }^{4} \text { Values shown in annual number of medical claims. }\end{array}$} \\
\hline
\end{tabular}

SHPT. Total health care costs were 320\% ( $\mathrm{p}<0.0001)$ higher in diabetic CKD patients with SHPT compared to those without SHPT.

\section{Survival Analysis}

Figure 1 shows the Kaplan-Meier analysis of time to death or dialysis combined according to the cohort of SHPT versus no SHPT. Diabetic CKD patients with SHPT progressed significantly more quickly to dialysis or death compared to those without SHPT. Cox proportional hazard analysis was conducted adjusted for relevant covariates. Diabetic CKD patients with SHPT had a nearly $7-$ fold greater risk of dialysis [hazard ratio $(\mathrm{HR})=6.7 ; 95 \%$ confidence interval $(\mathrm{CI})=4.3-10.6 ; \mathrm{p}<0.0001]$, more than twice the risk of death $(\mathrm{HR}=2.3 ; 95 \% \mathrm{CI}=1.1-4.9$; $\mathrm{p}=0.0301)$ and more than 5 times the risk of dialysis and/ or death $(\mathrm{HR}=5.2 ; 95 \% \mathrm{CI}=3.5-7.7$; $\mathrm{p}<0.0001)$, when compared to diabetic CKD patients without SHPT (table 3).

\section{Discussion}

Our findings suggest that diabetic predialysis CKD patients with SHPT experience a faster progression and higher risk of dialysis or death compared to diabetic pre- 


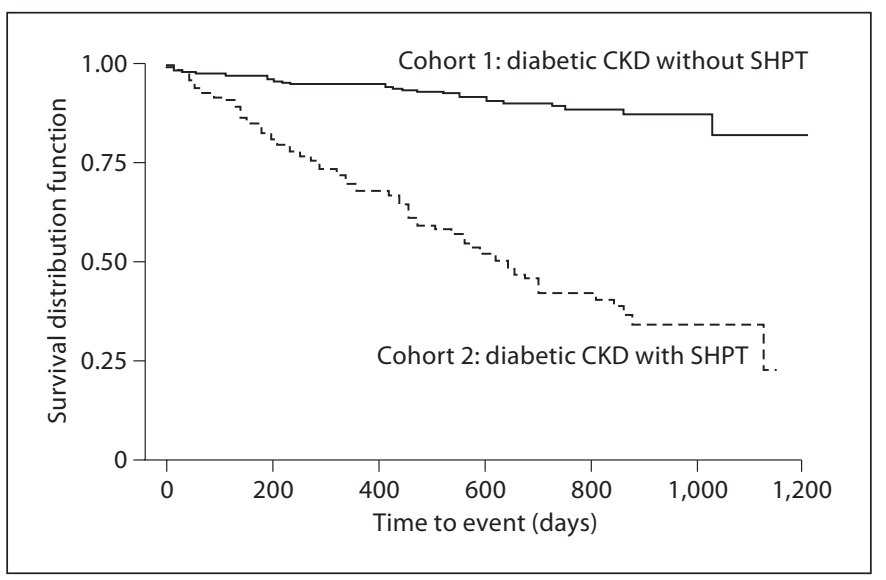

Fig. 1. Kaplan-Meier analysis shows the disease progression to either dialysis or death of patients without SHPT, compared to those with SHPT.

dialysis CKD patients without SHPT. We also found that these patients (with SHPT) utilized more health care resources (including prescriptions, outpatient services and hospitalizations) and consumed higher costs of care compared to those without SHPT.

To the best of our knowledge, this is the first study to have investigated kidney disease progression associated with SHPT in diabetics with predialysis CKD. This is an underappreciated patient group, despite the fact that DM is the single leading cause of kidney failure in the USA, and many other countries [2], whereas SHPT is grossly underdiagnosed in predialysis CKD patients [8]. The prevalence of SHPT in patients with an estimated glomerular filtration rate less than $60 \mathrm{ml} / \mathrm{min}$ is approximately $56 \%$ [13]. Our study demonstrates the economic burden of SHPT in diabetic predialysis CKD patients and the negative impact on disease progression. Previous studies have shown the economic advantage and improvement in survival of selective VDRA therapy in CKD stage 5 hemodialysis patients [14-18]. Further analyses are needed to assess whether early treatment with a selective VDRA in diabetic predialysis CKD patients can reduce such excessively high costs and positively impact the disease progression and clinical outcomes including survival.

The number of patients with diabetes as the primary cause of CKD stage 5 (traditionally known as end-stage renal disease) rose $6.6 \%$ between 2001 and 2005 [7]. In both diabetic and nondiabetic CKD patients, elevated parathyroid hormone has been shown to be associated with a number of cardiovascular (myocardial fibrosis, left-ventricular hypertrophy, decreased myocardial contractility, increased vascular and valvular calcification, decreased vasodilatation), metabolic (decreased insulin sensitivity and disorders of lipid metabolism, hematological (bone marrow fibrosis and decreased erythropoiesis) and immunological abnormalities [19]. Hence it is biologically and epidemiologically plausible that untreated SHPT in diabetic predialysis patients would lead to greater health care resource utilization and disease progression.

The goal (a priori) was to match 4:1; however, we were not able to find 4 matches for each SHPT patient. Consequently, in order to maximize sample size of the patients included in the study, we required at least 1 match and up to 4 matches for each SHPT patient. The average match was 2.8:1.

For a patient to be defined as diabetic we required at least 2 diagnosis codes of DM (at least 30 days apart) or 1 claim plus a prescription for a diabetic medication. We did this in order to eliminate 'rule-out' patients from the study. In our experience, it is common for a diagnosis of diabetes to be present on an outpatient management claim or laboratory claim if the physician suspects DM. Typically, the physician will then order a laboratory test to confirm the diagnosis, and a second diagnosis code will appear in the record. If only a single diagnosis code is present in the claims data (and if there are no diabetes medications filled), then the patient may have been ruled out for diabetes, and thus we did not define them as confirmed DM cases.

Our study is subject to the inherent limitations of epidemiological observational studies and only associations, not causality, can be inferred. We preformed strategies to mitigate confounding by other factors such as selecting the first diagnosis for CKD as the index date and adjusting for Charlson comorbidity index and preindex health care costs to correct for CKD severity between the cohorts. This analysis was conducted by developing the study protocol and analysis plan a priori [20]. Further, the accuracy of coding within claims data is known to be variable, particularly with respect to diagnoses where miscoding may be problematic. We used ICD-9 codes to identify patients with diabetes, CKD and SHPT, and as such our results are reliant on the quality of coding.

Both Customer-Centric Initiative (CCI) and preindex health care costs were considered appropriate variables to control for in measuring the risk of dialysis as well as resource utilization/cost in the follow-up period. No collinearity issues were found when conducting and testing the models. Descriptive analyses were examined and de- 
Table 3. Cox proportional hazards model of the risk of dialysis and/or death

\begin{tabular}{|c|c|c|c|c|}
\hline \multirow[t]{2}{*}{ Variable } & \multirow[t]{2}{*}{ HR } & \multicolumn{2}{|l|}{$95 \% \mathrm{CI}$} & \multirow[t]{2}{*}{$\mathrm{p}$ value } \\
\hline & & lower limit & upper limit & \\
\hline Cohort 2 (CKD with SHPT) vs. cohort 1 (CKD without SHPT) & 5.20 & 3.51 & 7.69 & $<0.0001$ \\
\hline Male vs. female & 1.27 & 0.86 & 1.87 & 0.2328 \\
\hline \multicolumn{5}{|l|}{ Age } \\
\hline $18-34$ vs. $\geq 65$ years & 0.74 & 0.07 & 7.93 & 0.8011 \\
\hline $35-44$ vs. $\geq 65$ years & 0.80 & 0.09 & 6.96 & 0.8360 \\
\hline $45-54$ vs. $\geq 65$ years & 0.38 & 0.05 & 3.18 & 0.3751 \\
\hline $55-64$ vs. $\geq 65$ years & 0.46 & 0.06 & 3.61 & 0.4589 \\
\hline Indemnity vs. HMO & 1.18 & 0.50 & 2.80 & 0.7135 \\
\hline PPO vs. HMO & 0.88 & 0.52 & 1.51 & 0.6518 \\
\hline POS vs. HMO & 0.55 & 0.26 & 1.17 & 0.1199 \\
\hline Medicaid vs. commercial & 0.59 & 0.25 & 1.40 & 0.2290 \\
\hline Medicare risk vs. commercial & 0.35 & 0.05 & 2.70 & 0.3159 \\
\hline Self-insured vs. commercial & 1.12 & 0.33 & 3.88 & 0.8562 \\
\hline Unknown vs. commercial & 2.52 & 0.73 & 8.76 & 0.1454 \\
\hline General/family practice vs. nephrology & 0.32 & 0.15 & 0.66 & 0.0019 \\
\hline Internal medicine vs. nephrology & 0.54 & 0.31 & 0.96 & 0.0369 \\
\hline Endocrinology vs. nephrology & 0.31 & 0.11 & 0.86 & 0.0242 \\
\hline Cardiology vs. nephrology & 0.42 & 0.18 & 0.98 & 0.0446 \\
\hline Other vs. nephrology & 0.85 & 0.51 & 1.41 & 0.5226 \\
\hline Unknown vs. nephrology & 0.61 & 0.32 & 1.19 & 0.1469 \\
\hline Northeast vs. west & 0.53 & 0.19 & 1.48 & 0.2256 \\
\hline Midwest vs. west & 0.58 & 0.32 & 1.06 & 0.0752 \\
\hline South vs. west & 0.61 & 0.31 & 1.20 & 0.1516 \\
\hline \multicolumn{5}{|l|}{ Preindex diagnosis of } \\
\hline Infectious and parasitic diseases & 0.88 & 0.56 & 1.38 & 0.5730 \\
\hline Neoplasms & 0.75 & 0.43 & 1.32 & 0.3193 \\
\hline Blood and blood-forming organ disorders & 1.92 & 1.23 & 3.00 & 0.0042 \\
\hline Mental disorders & 0.81 & 0.49 & 1.35 & 0.4227 \\
\hline Nervous system and sense organ disorders & 1.19 & 0.82 & 1.73 & 0.3611 \\
\hline Circulatory system disorders & 1.48 & 0.84 & 2.62 & 0.1797 \\
\hline Respiratory system disorders & 0.98 & 0.66 & 1.46 & 0.9292 \\
\hline Digestive system disorders & 0.67 & 0.43 & 1.03 & 0.0682 \\
\hline Genitourinary system disorders & 0.67 & 0.45 & 1.01 & 0.0558 \\
\hline Skin/subcutaneous tissue disorders & 0.95 & 0.63 & 1.43 & 0.8146 \\
\hline Musculoskeletal system disorders & 0.86 & 0.59 & 1.26 & 0.4303 \\
\hline $\log ($ total preindex costs $)$ & 1.18 & 0.99 & 1.41 & 0.0731 \\
\hline
\end{tabular}

$\mathrm{PPO}=$ Preferred provider organization; $\mathrm{HMO}=$ health maintenance organization; POS = point of service.

termined that the difference in CCI was significant and therefore needed to be in the model. It can be argued that the CCI adjustment (as an adjustor for preindex disease severity) would have sufficed. However, the preindex health care cost adjustment added value by capturing all costs, not just certain conditions as captured in the CCI.

Identification of patients with SHPT was particularly challenging, because SHPT is not often coded. Therefore, we labeled patients as having SHPT if they had a specific diagnosis of SHPT (ICD-9 code 588.8x), a diagnosis of hyperphosphatemia (ICD-9 code 275.3) or were receiving phosphate binder treatment during the postindex (CKD diagnosis) period. This definition of SHPT may still not be adequately inclusive, and as such there is the possibility of undiagnosed SHPT in the reference cohort. However, this limitation suggests that even greater differences between cohorts may exist.

We also used claims data to identify the events of interest. Since the claims database we used did not provide an indicator of death, a previously published proxy for 
death in end-stage renal disease patients was used [10]. The use of this proxy indicator may be subject to misclassification error. However, this method has been validated and used frequently $[11,12]$. Selection bias, bias from censoring of data and measurement error are other potential sources of miscalculation. Nevertheless, we have no reason to suspect that selection bias influenced our results. We censored the data to ensure internal consistency of patients included and for interpretability of our results.

\section{Conclusion}

In this retrospective observational study, we found that in diabetic predialysis CKD patients, the concurrent existence of SHPT without VDRA therapy is associated with significantly greater health care resource utilization and costs, a faster rate of CKD progression and an increased risk of death. While there are limita- tions of this type of analysis, these results provide preliminary evidence of the additional burden of SHPT in the presence of diabetes and CKD, and perhaps indicate the need for additional studies to both confirm these findings and evaluate the ability of treatment of SHPT in diabetic stage 3 and 4 CKD patients to lessen this burden.

\section{Conflicts of Interest}

G.T.S. has received grants and/or honoraria from Abbott, manufacturer of paricalcitol (Zemplar $\left.{ }^{\mathrm{TM}}\right)$. K.K.-Z. has received grants and/or honoraria from: Abbott; Genzyme, manufacturer of selvelamer (Renagel ${ }^{\mathrm{TM}}$ and Renvela ${ }^{\mathrm{TM}}$ ) and doxercalciferol (Hectorol ${ }^{\mathrm{TM}}$ ); Shire Pharmaceutical, manufacturer of lanthanum carbonate (Fosrenol ${ }^{\mathrm{TM}}$ ), and/or Amgen, manufacturer of cinacalcet (Sensipar $\left.{ }^{\mathrm{TM}}\right)$. D.L.A., S.E.M. and R.S. are employees of Abbott. A.T.J. is an employee of PharMetrics Inc. PharMetrics Inc. was paid by Abbott to conduct the analyses presented in this article.

\section{References}

1 Steinbrook R: Facing the diabetes epidemic - mandatory reporting of glycosylated hemoglobin values in New York City. N Engl J Med 2006:354:545-548.

2 Centers for Disease Control: National diabetes fact sheet, United States 2005. http:// www.cdc.gov/diabetes/pubs/pdf/ndfs 2005.pdf (accessed January 2, 2008, last modified February 2, 2006).

3 Centers for Disease Control: Diabetes data and trends. http://www.cdc.gov/diabetes/ statistics/incidence/fig1.htm (accessed January 2, 2008, page last reviewed March 26, 2007).

4 National Center for Health Statistics: Deaths - leading causes (2005). US Department of Health and Human Services, Centers for Disease Control. http://www.cdc.gov/nchs/ fastats/lcod.htm (accessed January 2, 2008, page last updated December 31, 2007).

5 National Kidney Foundation: Diabetes and kidney disease. http://www.kidney.org/kidneydisease/diabetesckd/index.cfm (accessed January 2, 2008).

6 Coresh J, Astor BC, Greene T, Eknoyan G, Levey AS: Prevalence of chronic kidney disease and decreased kidney function in the adult US population: Third National Health and Nutrition Examination Survey. Am J Kidney Dis 2003;41:1-12.

7 US Renal Data System, USRDS 2007 Annual Data Report: Atlas of Chronic Kidney Disease and End-Stage Renal Disease in the United States. Bethesda, National Institutes of Health, National Institute of Diabetes and Digestive and Kidney Diseases, 2007.
8 Kalantar-Zadeh K, Marx SE, Schumock G, Bocuzzi SJ, Blount A, Sterz R, Melnick JZ, Williams LA: Examination of outcomes and costs of care among patients with chronic kidney disease and secondary hyperparathyroidism. J Am Soc Nephrol 2006;17:647A.

92003 ICD-9-CM Professional for Physicians, ed 6. Reston, Ingenix, 2003, vol 1 and 2.

10 Joyce AT, Iacoviello JM, Nag S, Sajjan S, Jilinskaia E, Throop D, Pedan A, Ollendorf DA, Alexander CM: End-stage renal diseaseassociated managed care costs among patients with and without diabetes. Diabetes Care 2004;27:2829-2835.

11 Pelletier EM, Shim B, Goodman S, Amonkar MM: Epidemiology and economic burden of brain metastases among patients with primary breast cancer: results from a US claims data analysis. Breast Cancer Res Treat 2008; 108:297-305.

12 Fintel D, Joyce A, Mackell J, Graff J, Kuntze E, Ollendorf DA: Reduced mortality rates after intensive statin therapy in managed-care patients. Value Health 2007;10:161-169.

13 Levin A, Bakris GL, Molitch M, Smulders M, Tian J, Williams LA, Andress DL: Prevalence of abnormal serum vitamin D, PTH, calcium, and phosphorus in patients with chronic kidney disease: results of the study to evaluate early kidney disease. Kidney Int 2007; 71:31-38.

14 Dobrez DG, Mathes A, Amdahl M, Marx SE, Melnick JZ, Sprague SM: Paricalcitol-treated patients experience improved hospitalization outcomes compared with calcitriol-treated patients in real-world clinical settings. Nephrol Dial Transplant 2004;19:1174-1181.
15 Rosery H, Bergemann R, Marx SE, Boehnke A, Melnick J, Sterz R, Williams L: Healtheconomic comparison of paricalcitol, calcitriol and alfacalcidol for the treatment of secondary hyperparathyroidism during haemodialysis. Clin Drug Invest 2006;26:629638.

16 Schumock GT, Arruda JA, Marx SE, Melnick JZ, Sterz R, Williams LA: Pharmacoeconomic analysis of paricalcitol and calcitriol in the treatment of secondary hyperparathyroidism in haemodialysis: impact of hospitalizations and survival. J Med Econ 2007; 10:393409.

17 Teng M, Wolf M, Lowrie E, Ofsthun N, Lazarus JM, Thadhani R: Survival of patients undergoing hemodialysis with paricalcitol or calcitriol therapy. N Engl J Med 2003;349: 446-456.

18 Kalantar-Zadeh K, Kuwae N, Regidor DL, Kovesdy CP, Kilpatrick RD, Shinaberger CS, McAllister CJ, Budoff MJ, Salusky IB, Kopple JD: Survival predictability of time-varying indicators of bone disease in maintenance hemodialysis patients. Kidney Int 2006;70:771-780.

19 Kovesdy CP, Kalantar-Zadeh K: Vitamin D receptor activation and survival in chronic kidney disease. Kidney Int 2008;73:13551363.

20 Arnold RG, Kotsanos JG, Motheral B, Ramsey S, Crown W, Puder K, Hornbrook $\mathrm{M}$, Wright A, Murray M: Methodological issues in conducting pharmacoeconomic evaluations - retrospective and claims database. Value Health 1999:2;82-87. 